\title{
Testing the random walk hypothesis of stock indexes through variance- ratio
}

\author{
Sadi Fadda, PhD
}

\section{Article Info}

Received Dec 3, 2018

\section{Keyword:}

Random Walk Hypothesis

Variance Ratio

Stock Indexes

\begin{abstract}
The Random Walk is considered to be a tool trying to explain the characteristic of movement of prices in the financial markets. It can also be seen in the form of a trial to demonstrate the non-predictability of future changes in the financial markets through reliance on the characteristics identified based on past price changes. In this paper used is the variance-ratio test initiated by Lo and MacKinlay to test the Random Walk Hypothesis for a more recent data of eleven Stock Indexes, seen as main indexes of the current market.
\end{abstract}

\section{INTRODUCTION}

As any investor would wish to be able to predict the movement direction of some asset price, the Random Walk Hypothesis argues it not to be a realistic option. Just as the name itself suggests, the assumption of the Random Walk Hypothesis (RWH) is that the prices experience change (walk) in an unpredictable direction and measure. The expected return should remain the same, and the covariance between any two separate returns should always be 0 . The initiator of the RWH was [1].

Informationally Efficient Market defines a market where all the relevant information that impacts the price of a financial instrument is available to everyone at no additional cost. The efficient market hypothesis (EMH) states that all the share prices are a reflection of its relevant information, whereby the stocks trade at the price they are worth. As such, no investor can outperform the market, whether by buying an undervalued share or by selecting the timing, instead, the only way to consider a higher return is by taking investment with higher risk. The weak form efficiency, also known as a random walk, corresponds to the situation where the data of past changes in price and the volume of trade have no impact on the current stock prices.

The weak-form efficiency of a market is frequently checked, in the existing literature of financial markets, within the framework of the random walk hypothesis. References [2] and [3] considered the Random Walk as a tool trying to explain the characteristic of movement of prices in the financial markets. It can also be seen as somewhat a trial to demonstrate the non-predictability of the future direction of price in the financial markets through reliance on the characteristics identified based on the previous changes.

As explained by Ref. [4], the price should follow a random walk since its changes take place as a reaction to new information in the market. Accordingly, just as the news itself, the price should be unpredictable. The initiator of the academic research on the random walk hypothesis was [5], who demonstrated that the Informationally Efficient Market should have unpredictable future price changes. On the other hand, Grossman and [6] argue on the actual cost of getting the market information, while explained was the effect of trading costs by [7]. 
Reference [8] puts it that the level of the market efficiency should match with its randomness in a change of prices, as such the most efficient market should have unpredictable random changes. Reference [9] concluded that the markets should be less distant from a random walk benchmark when markets are more liquid, mainly due to the arbitrage.

On the other hand, rejection of the random walk hypothesis would imply an impact of market shocks on a long period through affecting the macroeconomic outcomes. Such kind of research, about market-shocks longrun effects, was done by among others Refs. [10], [11], and [12]. Similarly, it would contradict the Volatility Clustering characteristic that substantial single-period changes in prices are more likely to be followed by significant changes. The first to report the volatility clustering was by [13] and [14] and later confirmed by numerous studies including [15], [16], and [17].

Initiators of the variance-ratio test as the method for hypothesis testing were Lo and MacKinlay [18], where they tested the US Indices market using the weekly data from 1962 to 1985 . Their conclusion was rejecting the random walk hypothesis. As for European markets, Worthington and Higgs included twenty countries in their research [19], where among the included sixteen developed markets only five (Germany, Ireland, Portugal, Sweden, and Britain) complied with the RWH. The emerging markets have previously been tested by Ayadi and Pyun for Korea [20], by Huang for eight selected Asian markets [21], as well as [22] by Urrutia for four Latin American markets of Argentina, Brazil, Chile, and Mexico. As in Ref. [23] for Taiwan, Chang and Ting analyzed the weekly price movements from 1971 to 1996 of the (TAIEX) Taiwan stock market index, using the Lo and MacKinlay variance-ratio test, rejecting the Random Walk Hypothesis.

Reference [24] studied the Istanbul Stock Exchange daily data for a sample of 20 stocks over the four-year period from the beginning of 1988 until the end of 1991, concluding that equity prices did not follow a random walk, through carrying the tests on independence, randomness, and normality. Ref. [25] rejected the random walk hypothesis for Jordan, Morocco, Egypt, Israel, and Turkey. Covered were five Eastern European countries by Smith and Ryoo, including Greece, Hungary, Poland, Portugal, and Turkey throughout the 1990s using the weekly data, where Istanbul Stock Exchange National-100 Index was the only one not to reject the hypothesis.

Dockery and Kavussanos researched Athens market [26], using the weekly price of 73 different equities for the period between Feb.1988 till October 1994, rejecting the random walk hypothesis. Similar outcome of rejecting the random walk hypothesis was reached by Awad and Daraghma for the Palestinian Securities Market [27]. Similarly, using non-parametric tools, reference [28] rejects the random walk hypothesis for both the Dubai Financial Market (DFM) and the Abu Dhabi Securities Market (ADSM).

It might also be worth mentioning that the analyzed data includes the period of the two years of the global financial crises (2008-2009), which according to the reference [29] should not have influenced the random walk behavior.

\section{METHODOLOGY}

Considering the time series of the return $\mathrm{r}$, and an interval of k-periods, then under Random Walk Hypothesis (RWH) the expected value of single-period-returns should be constant, and their distribution should be uncorrelated, such that

$$
E\left[r_{t}\right]=E\left[r_{t+k}\right] \text { and } \operatorname{cov}\left(r_{t}, r_{t+k}\right)=0, \forall t, k>0
$$

Accordingly, the best forecast is seen to be the mean value or $E\left[r_{t}\right]$, so for the next period forecast of return $\mathrm{f}_{\mathrm{t}+1}$

$$
f_{t+1}=\mu+\sum_{i=0}^{\infty} \alpha_{i} r_{t-i}
$$

The optimal solution would be the pair of $\mu=\mathrm{E}\left[\mathrm{r}_{\mathrm{t}}\right]$ and $\alpha_{\mathrm{i}}=0 \forall \mathrm{i}$. In other words, the mean value of return is the best optimal forecast for any future period, and any deviation from that would increase the measure of error. Assuming the mean of returns being stationary ensures the consistency in the estimates of the autocorrelations of returns samples. 


\subsection{RANDOM WALK TEST}

Relying on [30], used is the following method of testing the random walk hypothesis through reliance on the variance-ratio.

Considering the returns to be stationary, the return variance for two periods $V(2)$, is calculated based on the variance of each of the two periods; where considering a single period variance of $V(1)=\operatorname{var}\left(r_{t}\right)$, then

$$
V(2)=\operatorname{var}\left(r_{t}\right)+\operatorname{var}\left(r_{t+1}\right)+2 \operatorname{cov}\left(r_{t}, r_{t+1}\right)
$$

Given the returns being stationary, and subsequently, the time does not affect variance, and then the Eq. (3) can be simplified as

$$
V(2)=\left(2+2 \rho_{1}\right) V(1)
$$

Where the $\rho_{1}$ represents the first lag autocorrelation of two single-period returns. As such, the calculation of the two-period variance ratio VR (2) is

$$
V R(2)=\frac{V(2)}{2 \times V(1)}=1+\rho_{1} .
$$

In case of the random-walk-hypothesis holding, the autocorrelation $\rho_{1}$ would be equal to zero, and hence the variance ratio of two consecutive periods $\operatorname{VR}(2)=1$.

For $\mathrm{N}$ periods, then as covariance $=0$, their variance would be equal to the sum of the $\mathrm{N}$ single period variances,

$$
V(N)=\operatorname{var}\left(r_{t}\right)+\operatorname{var}\left(r_{t+1}\right)+\cdots+\operatorname{var}\left(r_{t+N-1}\right)=N \times V(1)
$$

Accordingly, the Variance Ratio, with the random walk hypothesis holding, would be

$$
\operatorname{VR}(\mathrm{N})=\frac{V(N)}{N \times V(1)}=1
$$

Otherwise, if the random walk hypothesis does not hold, then, as covariance differs from zero, it is included in the calculation of the N-periods Variance

$$
V(N)=\mathrm{N} \times \mathrm{V}(1)+2 \sum_{\mathrm{i}=1}^{\mathrm{N}-1} \sum_{\mathrm{j}=\mathrm{i}+1}^{\mathrm{N}} \operatorname{cov}\left(r_{t+i-1}, r_{t+j-1}\right)
$$

While in practice, the proper estimation can be done by

$$
V(N)=\frac{n}{(n-N)(n-N+1)} \sum_{t=1}^{n-N+1}\left(r_{t}+r_{t+1}+\ldots+r_{t+N-1}-N \bar{r}\right)^{2}
$$

Simplified double summation in Eq. (8) for $V(N)$ provides the Variance Ratio to be

$$
V R(N)=\frac{V(N)}{N \times V(1)}=1+\frac{2}{N} \sum_{\tau=1}^{N-1}(N-\tau) \rho_{\tau}
$$

Calculation of such Variance Ratio, which supposes RWH not to hold, provides a tool for testing the correctness of Random Walk Hypothesis. The more distant the VR is from the value of 1, the stronger the argument becomes for rejecting the RWH. Taken are the following estimates with the assumption that RWH is true. By accurately approximating the variance of $V R(N)$ corresponding to the equation (10), the same can be considered to be a good approximation of the variances of the preceding $\mathrm{N}-1$ autocorrelations of $\rho_{\tau}$. Estimation of $n \operatorname{var}\left(\rho_{\tau}\right)$ is done by

$$
\begin{aligned}
& b_{\tau}=\frac{n \sum_{t=1}^{n-\tau} s_{t} s_{t+\tau}}{\left(\sum_{t=1}^{n} s_{t}\right)^{2}} \\
& s_{t}=\left(r_{t}-\bar{r}_{t}\right)^{2}
\end{aligned}
$$

The reliable approximation of $b_{\tau}$ is attained through the kurtosis value of returns, $k$, in addition to the autocorrelations $\rho_{\tau}$ of $s_{\mathrm{t}}$

$$
b_{\tau} \cong 1+(k-1) \rho_{\tau} .
$$

The same is then used to estimate variance-ratios multiplied by the sample size of $n$, based on the selected value of $\mathrm{N}$, by 


$$
v_{N}=\frac{4}{N^{2}} \sum_{\tau=1}^{N-1}(N-\tau)^{2} b_{\tau} \cong n \operatorname{var}(\operatorname{VR}(N))
$$

As a final point, the sample variance ratio estimated standardized distribution, whose estimation is dependent on the sample size n, and calculated by Eq. (15), which is used to determine the random-walk hypothesis.

$$
z_{N}=\frac{V R(N)-1}{\sqrt{v_{N} / n}}
$$

\section{TESTING THE SELECTED INDEXES DATA}

Among the conditions for the reliability of the test is that ' $\mathrm{n} / \mathrm{N}$ ' be as large as possible, while preferably more than one hundred. Available is a more detailed study on the efficiency of analyzing the variance-ratio in [31], [32], and [33]. Campbell et al. (1997).

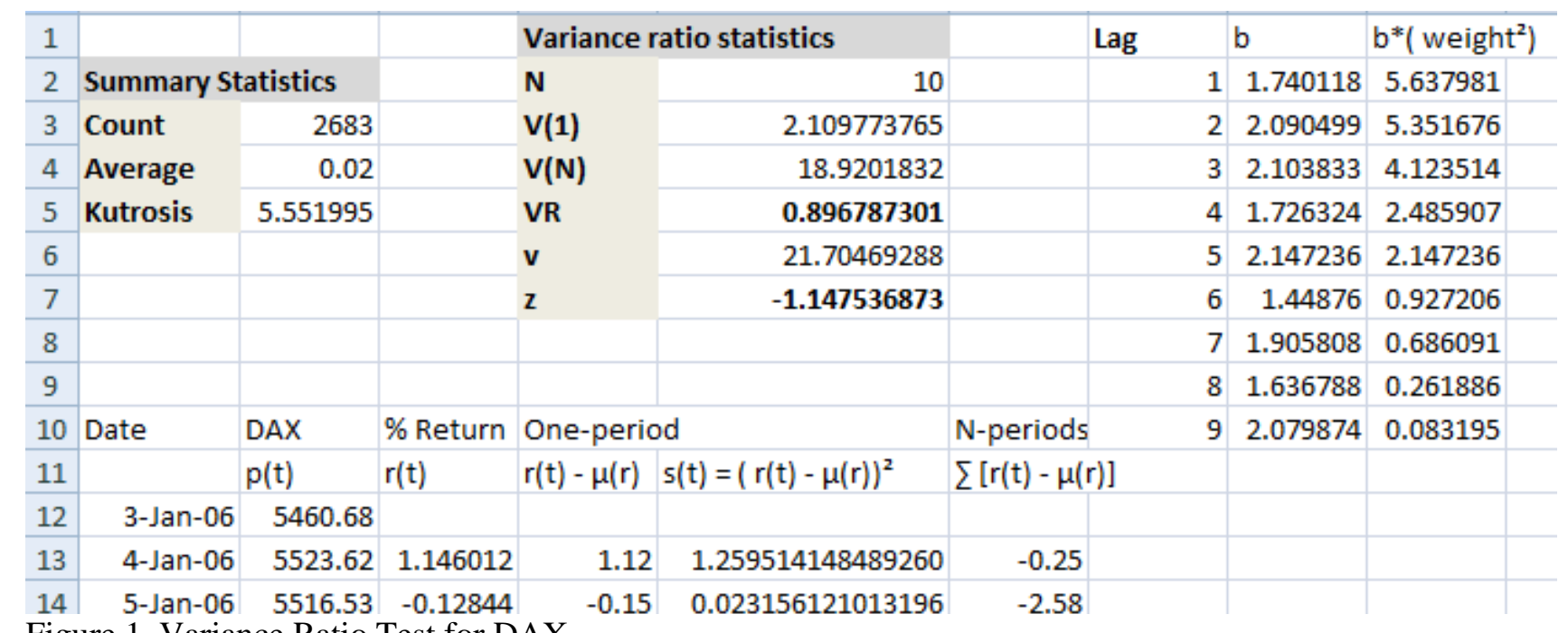

Figure 1. Variance Ratio Test for DAX

The calculation was done using the Microsoft Excel, and the daily closing price of the 11 selected Stock Indexes. Figure 1, shows the calculation sheet of excel, and its main outcomes for the German Index of XETRA DAX. The V (1), or single period variance, calculates the variance of the set of daily returns. The V $(\mathrm{N})$, which is the variance of returns for $\mathrm{N}$ periods, would be estimated using the equation (9). Finally, the Variance Ratio (VR), gets calculated by dividing multiple-periods-variance $\mathrm{V}(\mathrm{N})$ by a single period variance $\mathrm{V}$ (1) and then dividing that result by $\mathrm{N}$.

As Excel provides the option to get the value of Kurtosis, it is used to calculate the corresponding value of the daily returns. The returns kurtosis is to be used to estimate the amount of $b_{\tau}$ through using the Eq. (13). Then the equation (14) is used to determine the variance of $n$ variance-ratios. As the final step, those previously calculated are used to estimate the standardized distribution using Eq. (15).

Practical application of the same calculation process was using around ten years of daily data of closing price of 11 different Stock Indexes. Collected were the historical data of daily closing prices of those indexes through Google Finance. Those include four American Indexes of Standard \& Poors 500, NASDAQ, Dow Jones Industrial, and New York Stock Exchange Composite Index (NYA). Added to that list are four European Indexes of British "The Financial Times Stock Exchange" FTSE100, French "Cotation Assistée en Continu" CAC40, German DAX, and Spanish IBEX35. Moreover, analyzed are three Asian Indexes of Japanese Nikkei, Chinese HANG SENG, and Indian BSE30. 


\section{RESULTS}

Table 1 shows the calculated values of a single period variance $V(1)$, five periods variance $V(5)$, the VarianceRatio (VR), as its name suggests, is the ratio between the first two calculated as $\mathrm{V}(5) /[5 \times \mathrm{V}(1)]$, and finally the standardized distribution estimation $\mathrm{z}_{\mathrm{N}}$. Finally added to the table is the kurtosis value of returns, describing each group spread from zero.

Table 1 Five Periods Variance Ratio Statistics for Indexes

\begin{tabular}{|l|r|r|r|r|r|}
\hline \multicolumn{1}{|c|}{ INDEXES } & $\mathbf{V}(\mathbf{1})$ & $\mathbf{V}(\mathbf{5})$ & \multicolumn{1}{c|}{$\mathbf{V R}$} & $\boldsymbol{z}_{\boldsymbol{N}=\mathbf{5}}$ & Kurt. \\
\hline SP500 & 1.66 & 6.58 & $\mathbf{0 . 7 9}$ & $\mathbf{- 2 . 5 9}$ & 10.4 \\
\hline Nasdaq & 1.92 & 8.03 & $\mathbf{0 . 8 3}$ & $\mathbf{- 2 . 3 7}$ & 7.9 \\
\hline DJI & 1.40 & 5.67 & $\mathbf{0 . 8 1}$ & $\mathbf{- 2 . 4 1}$ & 10.2 \\
\hline NYA & 1.84 & 7.58 & $\mathbf{0 . 8 2}$ & $\mathbf{- 2 . 2 2}$ & 9.9 \\
\hline DAX & 2.11 & 10.08 & 0.96 & -0.76 & 5.6 \\
\hline CAC40 & 2.27 & 9.78 & $\mathbf{0 . 8 6}$ & $\mathbf{- 2 . 3 6}$ & 5.7 \\
\hline FTSE100 & 1.56 & 6.74 & $\mathbf{0 . 8 6}$ & $\mathbf{- 2 . 0 0}$ & 7.2 \\
\hline IBEX35 & 2.57 & 12.00 & 0.93 & -1.18 & 6.7 \\
\hline HANG & & & & & \\
SENG & 2.56 & 11.96 & 0.93 & -0.81 & 8.7 \\
\hline NIKKEI & 2.64 & 11.83 & 0.90 & -1.39 & 7.3 \\
\hline BSE 30 & 2.40 & 12.18 & 1.02 & 0.27 & 9.1 \\
\hline
\end{tabular}

As in all cases, the sample size $\mathrm{n}$ includes more than 2600 daily returns, as such, for the values of $\mathrm{N}=5$, and $\mathrm{N}=10$ it can be considered reliable, since having $\mathrm{n} / \mathrm{N}=260$, which is higher than 100 . Correspondingly, the conclusions do not change by the change of $\mathrm{N}$ value from 5 to 10 , despite change in the measures of both the calculated outcomes of variance ratio VR and resultant $\mathrm{z}_{\mathrm{N}}$.

These results show that indexes of DAX, IBEX35, HANG SENG, BSE30, and Nikkei do not reject the hypothesis of a random walk with a significance level of 0.05 , as the $\mathrm{z}_{\mathrm{N}}$ values for each of them falls within the symmetric range of the standard normal distribution, between -1.96 and 1.96, covering the confidence level of $95 \%$.

On the other hand, the daily returns of all four American indexes of S\&P500, DJI, NYA, and NASDAQ100 variance-ratio tests provide their $\mathrm{z}_{\mathrm{N}}$ value outside the favored range. In all four cases, it occurred to be less than -1.96 and accordingly conclusive of rejection of the random walk hypothesis. Likewise, the remaining two European indexes of French CAC40 and British FTSE100 reject the random walk hypothesis.

Just in parallel to the outcomes of random walk hypothesis testing with $\mathrm{N}=5$, taking into consideration ratio of ten trading days to one trading day $(\mathrm{N}=10)$, as shown in Table 2, conclusions of rejecting or not the hypothesis were entirely the same. The only noticeable differences are their values of the variance ratio VR (5) versus VR (10), as well as the standardized distribution of theirs $\mathrm{z}_{\mathrm{N}=5}$ compared to $\mathrm{z}_{\mathrm{N}=10}$.

While Bombay Stock Exchange (BSE30) is the only of studied indexes to have variance ratio VR(5) greater than one, all the covered Indexes have the VR(10) less than one, they also show the variance ratio value decreasing, that is $\operatorname{VR}(5)>\operatorname{VR}(10)$ for every of those indexes. 
Table 2 Ten-Periods Variance Ratio Statistics for Indexes

\begin{tabular}{|l|l|l|l|l|}
\hline INDEXES & $\mathbf{V}(\mathbf{1})$ & $\mathbf{V}(\mathbf{1 0})$ & $\mathbf{V R}$ & $\boldsymbol{z}_{\boldsymbol{N}=\mathbf{1 0}}$ \\
\hline SP500 & 1.66 & 11.73 & $\mathbf{0 . 7 1}$ & $\mathbf{- 2 . 3 3}$ \\
\hline Nasdaq & 1.92 & 15.02 & $\mathbf{0 . 7 8}$ & $\mathbf{- 2 . 0 4}$ \\
\hline DJI & 1.40 & 10.16 & $\mathbf{0 . 7 3}$ & $\mathbf{- 2 . 2 1}$ \\
\hline NYA & 1.84 & 13.70 & $\mathbf{0 . 7 4}$ & $\mathbf{- 2 . 0 4}$ \\
\hline DAX & 2.11 & 18.92 & 0.90 & -1.15 \\
\hline CAC40 & 2.27 & 17.66 & $\mathbf{0 . 7 8}$ & $\mathbf{- 2 . 4 3}$ \\
\hline FTSE100 & 1.56 & 12.25 & $\mathbf{0 . 7 8}$ & $\mathbf{- 2 . 0 2}$ \\
\hline IBEX35 & 2.57 & 21.98 & 0.85 & -1.63 \\
\hline $\begin{array}{l}\text { HANG } \\
\text { SENG }\end{array}$ & 2.56 & 23.60 & 0.92 & -0.65 \\
\hline NIKKEI & 2.64 & $2(34$ & 0.84 & -1.36 \\
\hline BSE 30 & 2.40 & 23.20 & 0.97 & -0.31 \\
\hline
\end{tabular}

Interestingly, categorization of the indexes outcomes is possible geographically, by the continent belonging of each index. As for the American indexes, the increasing value of $\mathrm{N}$ from $\mathrm{N}=5$ to $\mathrm{N}=10$ moves the $\mathrm{z}$-value closer to the confidence interval (having $\mathrm{z}$ values between -1.96 and 1.96), whereas all four of them are negative, it increases in value. The opposite holds for European indexes, as the negative values of $\mathrm{z}$ instead move further from zero, decreases in value. The Asian indexes respond to the change of $\mathrm{N}$, from the value 5 to that of 10, in parallel with the European indexes.

\section{CONCLUSION}

The random walk hypothesis suggests that price movement in a stock market does not relate in any way to the past changes. It also indicates that future price can't be forecasted mathematically, by relying on historical information. This paper analyses how much the hypothesis holds in different markets, analysing their stock indexes as reliable indicators.

Rejection of the random-walk-hypothesis, based on the daily closing price from the beginning of 2006 until mid-2016, can be confirmed for two of four analyzed European indexes of CAC40 and FTSE100, as well as for all four American indexes included in this study (SP500, NASDAQ, DJI, and NYA). On the other hand, German DAX, Spanish IBEX35, and all three Asian Indexes of Japanese Nikkei, Chinese HANG SENG, and the Indian BSE30 do not reject the RWH for both of the considered values of $\mathrm{N}=5$, and $\mathrm{N}=10$.

An interesting finding of this paper is that all the tested US Indexes fail to accept the random walk hypothesis, given its being the market with the highest volume of trade. Other methods of testing the RWH are to be studied, and accordingly, the same set of indexes and the outcomes of this paper are to be analyzed further by using alternate methods, other than the variance-ratio. 


\section{REFERENCES}

[1] Granger CW, Morgenstern O. Predictability of stock market prices. Heath Lexington Books; 1970.

[2] Malkiel BG, Fama EF. Efficient capital markets: A review of theory and empirical work. The journal of Finance. 1970 May;25(2):383-417.

[3] Fama EF. Efficient capital markets: II. The journal of finance. 1991 Dec 1;46(5):1575-617.

[4] Malkiel BG. The efficient market hypothesis and its critics. Journal of economic perspectives. 2003 Mar;17(1):59-82.

[5] Samuelson PA. Proof that properly anticipated prices fluctuate randomly. Industrial management review. $1965 ; 6(2)$.

[6] Grossman SJ, Stiglitz JE. On the impossibility of informationally efficient markets. The American economic review. 1980 Jun 1;70(3):393-408.

[7] Roll R. A simple implicit measure of the effective bid- ask spread in an efficient market. The Journal of finance. 1984 Sep;39(4):1127-39.

[8] Lo, Andrew W. (2008). Efficient Markets Hypothesis. The New Palgrave Dictionary of Economics.

Second Edition. Eds. Steven N. Durlauf and Lawrence E. Blume. Palgrave Macmillan

[9] Chordia T, Roll R, Subrahmanyam A. Liquidity and market efficiency. Journal of Financial Economics. 2008 Feb 1;87(2):249-68.

[10] Campbell JY, Mankiw NG. Permanent and Transitory Components in Macroeconomic Fluctuations. The American Economic Review. 1987 May 1;77(2):111-7.

[11] Cochrane JH. How big is the random walk in GNP?. Journal of political economy. 1988 Oct 1;96(5):893920.

[12] Cogley T. International evidence on the size of the random walk in output. Journal of Political Economy. 1990 Jun 1;98(3):501-18.

[13] Mandelbrot B. New methods in statistical economics. Journal of political economy. 1963 Oct

1;71(5):421-40.

[14] Fama EF. The behavior of stock-market prices. The journal of Business. 1965 Jan 1;38(1):34-105.

[15] Chou RY. Volatility persistence and stock valuations: Some empirical evidence using GARCH. Journal of Applied Econometrics. 1988 Oct;3(4):279-94.

[16] Schwert GW. Why does stock market volatility change over time?. The journal of finance. 1989

Dec;44(5):1115-53.

[17] Baillie RT, Bollerslev T, Mikkelsen HO. Fractionally integrated generalized autoregressive conditional heteroskedasticity. Journal of econometrics. 1996 Sep 1;74(1):3-0.

[18] Lo AW, MacKinlay AC. Stock market prices do not follow random walks: Evidence from a simple specification test. The review of financial studies. 1988 Jan 1;1(1):41-66.

[19] Worthington AC, Higgs H. Random walks and market efficiency in European equity markets. Global Journal of Finance and Economics. 2004;1(1):59-78.

[20] Ayadi OF, Pyun CS. An application of variance ratio test to the Korean securities market. Journal of banking \& finance. 1994 Sep 1;18(4):643-58.

[21] Huang BN. Do Asian stock market prices follow random walks? Evidence from the variance ratio test. Applied Financial Economics. 1995 Aug 1;5(4):251-6.

[22] Urrutia JL. Tests of random walk and market efficiency for Latin American emerging equity markets. Journal of financial research. 1995 Sep;18(3):299-309.

[23] Chang KP, Ting KS. A variance ratio test of the random walk hypothesis for Taiwan's stock market. Applied Financial Economics. 2000 Sep 1;10(5):525-32.

[24] Muradoglu G, Unal M. Weak form efficiency in the thinly traded Istanbul Securities Exchange. The Middle East Business and Economic Review. 1994;6(2):37-44.

[25] Omran M, Farrar SV. Tests of weak form efficiency in the Middle East emerging markets. Studies in Economics and Finance. 2006 Apr 1;23(1):13-26.

[26] Dockery E, Kavussanos MG. Testing the efficient market hypothesis using panel data, with application to the Athens stock market. Applied Economics Letters. 1996 Feb 1;3(2):121-3.

[27] Awad I, Daraghma Z. Testing the weak-form efficiency of the Palestinian securities market. International Research Journal of Finance and Economics. 2009;32:7-17.

[28] Squalli J. A non-parametric assessment of weak-form efficiency in the UAE financial markets. Applied Financial Economics. 2006 Dec 1;16(18):1365-73. 
[29] Auer BR, Schuster M. Does the financial crisis influence the random walk behaviour of international stock markets?. Applied Economics Letters. 2011 Mar 9;18(4):319-23.

[30] Taylor SJ. Asset price dynamics, volatility, and prediction. Princeton university press; 2011 Feb 11. [31] Lo AW, MacKinlay AC. Stock market prices do not follow random walks: Evidence from a simple specification test. The review of financial studies. 1988 Jan 1;1(1):41-66.

[32] Lo AW, MacKinlay AC. The size and power of the variance ratio test in finite samples: A Monte Carlo investigation. Journal of econometrics. $1989 \mathrm{Feb}$ 1;40(2):203-38.

[33] Campbell JY, Lo AW, MacKinlay AC. The econometrics of financial markets. Princeton, NJ: princeton University press; 1997 Jan. 